\title{
The Landscape, Its Narrative Identity and Man's Well-Being
}

\author{
Dr. Vereno Brugiatelli
}

\begin{abstract}
In this study I intend to put forward a reflection on the landscape and, in particular, on the relationships that man establishes with it. From the European Landscape Convention (Florence, 20.X.2000), which considers the landscape a socio-cultural product, I aim to analyze this concept in order to determine: 1 . what the identity of a certain landscape consists of and what constitutes it; 2 . the relationship between the identity of the landscape and the identity of its inhabitants; 3 . the importance of the identity of the landscape when planning and implementing interventions to safeguard and enhance it; 4 . the ethical and cultural bases influencing urban planners and architects when intervening in the landscape; 5 . the importance of the landscape to man's wellbeing.
\end{abstract}

Keywords: Landscape; Identity of the landscape; Narrative; Innovation; Well-being.

\section{Introduction}

The European Landscape Convention (Florence, 20.X.2000) interprets, protects and enhances the landscape as a dynamic process of man's cultural relations with the environment and the territory; it states that the landscape is a social and cultural product. The Convention calls upon the citizens and institutions to identify suitable criteria, actions and objectives to promote the quality of the landscape. In order to achieve this, the citizens need to develop awareness, knowledge and responsibility with regard to the territory, environment and landscape. From these assumptions, in this study I aim to focus on: 1 . what the identity of a certain landscape consists of and what constitutes it; 2 . the relationship between the identity of the landscape and the identity of its inhabitants it; 3 . the importance of the identity of the landscape when planning and implementing interventions to safeguard and enhance it; 4 . the ethical and cultural bases influencing urban planners and architects when intervening in the landscape; 5 . the importance of the landscape to man's well-being.

\section{Territory, environment and landscape}

Territory, environment and landscape are distinct dimensions but, at the same time, they are closely linked. By "territory" we refer to the extension of the earth's surface with its morphological characteristics, which are often subject to man's intervention, and come to our knowledge through Geography. The term "environment" refers to all the biological conditions permitting the life of organisms including the presence of water, seasonal temperatures, altitude above sea-level, precipitation, latitude, longitude and the geological soil conformation etc. Furthermore, the term "environment" also has a historical-cultural meaning referring to the human dimension including agriculture, live-stock farming, industry, urban areas, cultural events, traces of past and present populations and artistic remains etc. The environment shapes and is inclusive of the territory, but the territory can do without the environment considered in both the biological and historical-cultural sense.

The landscape, in turn, includes the territory and the environment to which man's involvement can be added, in other words, the interventions of value and cultural works. Therefore, the cultural landscape can be considered a visible expression of the culture of the different populations that have shaped it. The cultural landscape presents itself to the observer in the form of sentimental, intellectual and spiritual interventions, which are dynamically linked together in the narrative memory (past), which, in turn, form the basis for (future) projects and present actions. The cultural landscape exhibits the distinctive characteristics of the culture of its inhabitants. These distinctive traits confer upon the landscape its features and identity thus distinguishing it from other landscapes. Each intervention in the landscape should, therefore, take into consideration the different elements competing to endow it with its specific identity. At this point, it is necessary to clarify how the identity of a landscape is formed and of what it consists. 


\section{The identity of a landscape}

The identity of a landscape and its formation can be likened to that of a person and that of a community of persons. In general, identity is intended as something that remains over time. Identity implies both the idea of equality and the idea of difference. It is not an immutable entity, to the contrary, it is a continuously evolving reality becoming recognizable despite the passage of time. The collective and individual identity building process is not achieved in isolation since it is of a social and cultural nature. It is defined through man's practical and interpretative relationships with others and with the territory and environment. As claimed by the philosopher Paul Ricoeur, identity is constructed in the dialectics between equality and difference (Ricoeur, 1994). It reflects the need to be identified, "to feel similar to..." and, to the contrary, the need to affirm uniqueness, "to be distinguished from..." (Remotti, 2001, p. 63). Man's identity emerges through difference by assimilation and distinction in social and cultural contexts and is formed by dynamic processes of circular interactions between man and the landscape. As far as the identity of a landscape is concerned, it is the result of cultural processes, interpretations and the narrative elaborated by populations over various generations. The European Landscape Convention highlights the landscape as the foundation of a population's identity and emphasizes the fact that, in turn, the population contributes to bestowing the landscape its identity. The cultural identity of a landscape emerges from a constant process of interpretations, narratives and actions. Two fundamental dimensions can be distinguished: 1. a specific dimension of a certain territory-environment; 2 . a socio-cultural dimension. The former dimension is made up of the measurable and quantifiable elements of a particular territory-environment such as temperature, altitude, longitude, presence of mountains, plains, valleys, lakes, rivers and the geological conformation of the territory etc.

All these aspects, examined by geologists and geographers, give the landscape specific characteristics, recognizable over long periods of time, and it is in this way that they contribute to the identity of the landscape. The latter socio-cultural dimension relates to the totality of man's actions and works on a particular territory-environment including pastoralism, agriculture, construction of roads, canals, urban areas, forts, dams, ports, monuments and places of worship. In short, it includes testimonies constituting the memories of man's relationships with the territory-environment and with other people. The socio-cultural dimension can profoundly affect the former by altering the identity of the landscape over a short period of time. The two dimensions are, therefore, closely linked through the theoretical and practical interactions between man and the territory-environment. However, these dimensions do not not yet fully constitute the identity of the landscape, only becoming so in the cultural narrative context. By building a narrative the quantitative aspects are linked to the sphere of man's socio-cultural actions. The identity of a landscape takes shape and is fully recognizable in the narrative, which is founded on man's interpretations at a territorial-environmental level and factors regarding man's actions with and on the territory-environment. Interpreting and narrating are fundamental procedures in forming the identity of a landscape thereby rendering a certain landscape recognizable for its distinctive and unique aspects, and differentiating it from other landscapes. From this viewpoint, the identity of a landscape is a narrative identity made up of a complex of interpretations and narratives elaborated over time.

The formation of a narrative identity implies the same process of settling and innovation underway in every tradition. For this reason, the narrative identity, if influenced by cultural and traditional elements, can be continuously reinterpreted. The narrative identity of the landscape, similarly to that of a person, is to be understood in a dynamic sense, as a continual historical-interpretative process evolving from new events and new interpretations.

\section{Identity, tradition and innovation}

But what is it that makes the landscape maintain its specific identity and continue to be recognizable as that landscape, despite the dynamic dimension of its narrative identity? Most interpretations are passed on through memory, which constitutes the basis of a tradition. Tradition is that which remains over time, representing a central theme for the narrative identity. However, traditions that are handed down from one generation to another in turn require interpretation, which involves innovation. There is a time for tradition and a time for interpretation. These two temporal dimensions are interrelated: a tradition stays alive thanks to its interpretation and, to a certain extent, the time for interpretation belongs to the timing of a tradition. There is a further third temporal dimension: the timing of sense. This temporality explains the significance of sense of the landscape making the intertwining of the two other temporalities possible. The sense temporality makes the continuous exchange between the transmission temporality (tradition) and the renewal temporality (interpretation) possible. The sense temporality is constituted by these two temporalities and, at the same time, adds to them: a sense potential adding to knowledge and to man's emotional, aesthetic, practical and interpretative participation in the landscape. The sense temporality confers value to the landscape providing man with a sentimental, intellectual and 
practical sense of affinity with the landscape. The timing of sense is the timing of cultural identity which includes the two former temporal dimensions exceeding them as far as its manifestation is concerned. A live tradition is one which, by embracing innovations, manages to warm the hearts of people, motivating them to interact with the landscape, thus enabling them to live and perceive the landscape as if it were part of them. Live tradition comprises innovation which introduces a new interpretation of the landscape aiming to reactivate some of its specific features in order to contribute to the extension of its potential of sense.

\section{Conserve or innovate?}

Continuous reciprocal exchanges and transformations take place between man, the environment and territory implying that any intervention in one of these dimensions affects the others. Thus, intervening on a territorial scale by building an artificial water reserve with a dam, for example, involves modifications to the environment and, consequently, to the entire landscape and the population. Therefore, any intervention should not only be based upon the knowledge and interpretations of the physical-territorial dimension, but also upon the biological-environmental and cultural dimensions. Territorial policies should encompass the environmental dimension and the complex of cultural aspects.

In Article 5 of the General measures the Convention calls for the recognition of the landscape as cultural identity and the following actions: "Each Party undertakes: a) to recognize landscapes in law as an essential component of people's surroundings, an expression of the diversity of their shared cultural and natural heritage, and a foundation of their identity; b) to establish and implement landscape policies aimed at landscape protection, management and planning through the adoption of the specific measures set out in Article $6 ; c$ ) to establish procedures for the participation of the general public, local and regional authorities, and other parties with an interest in the definition and implementation of the landscape policies mentioned in paragraph b) above; d) to integrate landscape into its regional and town planning policies and in its cultural, environmental, agricultural, social and economic policies, as well as in any other policies with possible direct or indirect impact on landscape". According to this perspective, landscape needs to be integrated into policies regarding environmental, territorial, urban, cultural, social and economic planning paying utmost attention to its distinctive and specific features while respecting the identity of places which add value. Conservation, recuperation and protection of a landscape's distinctive features are all factors which should be taken into account in landscape policies. Such actions need to be based on a well-informed and responsible interpretation of the territory, environment and landscape from the viewpoint of their general and specific aspects. As far as the landscape is concerned, care needs to be taken of both the general features it has in common with other landscapes together with its individual and unique characteristics, which distinguish it from other landscapes, making it recognizable as that landscape. Neglect, degradation and distortion of the nature of the landscape are often accompanied by the negligence and obscurity of such features. Their retrieval involves the rediscovery of narratives passed down and elaborated over time by the local inhabitants, who have transformed and constructed that landscape with its specific traits through their narratives. An unrecognizable landscape is a landscape that has lost such features and, with them, its narratives.

Landscape identity is therefore a "cultural identity" which is not only recognizable by its appearance but, above all, by its narratives. Appreciation of a landscape can not overlook the story forming its basis and constituting its narratives. In other words, viewing and admiring are subjective behaviours which come to life from the narratives elaborated by the various inhabitants. In order to recognize a landscape, the visual element cannot fail to consider the narratives. Without such references little would be understood about the landscape: much would be seen, but little would be fully appreciated. Recognizing a landscape is always a cultural process which can contribute to its renewal by reactivating the unique aspects that have either been obscured or simply never fully enhanced. From this point of view, it is not a matter of passing on the same narratives and, therefore, leaving an unaltered landscape over time. Obstructing any intervention in the landscape implies betraying the sense of tradition thus turning it into an abstract element of an a-historical and artificial nature. Recognizing the historical relationships between culture and landscape should not only involve conservation of the landscape and natural heritage with static duplication of the traditional forms of typical cultural and artistic expressions, but, on the other hand, it should stimulate new forms of interpretation of the landscape's specific, identifying characteristics in close connection with global-scale interpretations (Claval, 2001). In this case, complete enhancement of a particular landscape can be realized in relation to the global cultural panorama. Indeed, since ancient times man has acquired ideas for building from non-indigenous cultures thus contributing to the reinterpretation of the landscape and the redefinition of its identity by innovating its spirit, its memory and its traditions. This perspective is confirmed by the fact that, throughout 
the world, many landscapes are the result of transformations over time made by inhabitants of differing cultures, who have contributed to broadening the richness of sense and the natural heritage.

\section{Enhancing the landscape and man's well-being}

The enhancement of the landscape cannot be detached from actions aimed at promoting the safeguarding of the territory and environment. Enhancing the landscape does not only regard the aesthetic dimension as, together with safeguarding the territory and environment, it affects well-being. Once we have overcome the dominant cultural perspective that man is isolated from his territory-environment, he needs to be considered in terms of co-belonging to the territory-environmentlandscape. In this sense, territory, environment and landscape are also the result of man's transforming actions over time. In turn, man is what he is also by virtue of the transformations produced upon him by the territory-environment-landscape. From this viewpoint, close inter-relationships are formed between a population's collective and individual identity and the landscape involving reciprocal influences and transformations. While animals have an environment, only man possesses a landscape. Abundant neuro-scientific, psychological and philosophical research into the mind has shown that the dynamics of the psyche and cultural practices are closely correlated with the territory-environment-landscape. For this reason, I believe that a person's and a population's psychological well-being cannot disregard the territorial, environmental and landscape context in which they live. Neglect of the landscape and environment impoverishes man's life. Thus, it is for this reason that the enhancement of the landscape relates to aesthetics and, at the same time, the successful formation of an individual and collective identity.

Landscape has an impact on general well-being in so far as it plays a role in a person's daily life. In this regard, Prieur observes that "The landscape is a familiar part of everyone's daily scene and plays a part in people's sense of belonging to a particular place and a particular community. So on a conscious or even unconscious level it contributes to mental wellbeing." (Prieur, 2006, p.14). The landscape, with its territorial and environmental components, communicates with man both on a conscious and unconscious level; it is the result of a population's socio-cultural actions, but man's actions on the landscape, in return, have an emotional, psychological and sentimental-aesthetic effect. Devastating the landscape therefore means harming the population emotionally, sentimentally and psychologically leading to alienation and detachment both as far as the man-landscape relationship is concerned as well as man's relationships with others. This is due to the fact that the devastation of the landscape involves various forms of human fragmentation, relating to memory, sentimental and emotional connections, which have an effect on people's lives generally up to the point that they live a landscape as a "non-place".

In this sense, not only does environmental pollution have harmful consequences for people's health, but also landscape devastation does too, since it has a direct impact on the sense of being in the world and, therefore, on general well-being. Thus, caring for the landscape means caring for oneself.

\section{References}

[1] Bonesio, L. (2001²). Geofilosofia del paesaggio. Milano: Mimesis.

[2] Bonesio, L. (2002). Oltre il paesaggio. I luoghi tra estetica e geofilosofia. Bologna: Arianna.

[3] Lingiardi, V. (2017). Mindscapes. Psiche nel paesaggio. Milano: Raffaello Cortina Editore.

[4] Magnaghi, A. (2010). Il progetto locale. Torino: Bollati Boringhieri.

[5] Nora, P. (1984). "Entre mémoire et histoire: la problématique des lieux". In Nora P. et al., "Les lieux de mémoire". Paris: Gallimard.

[6] Prieur, M. (2006). "Landscape and social, economic, cultural and ecological approaches". In: Landscape and sustainable development. Challenges of the European Landscape Convention. Council of Europe Publishing: 11-28.

[7] Remotti, F. (2010). L'ossessione identitaria. Roma-Bari: Laterza.

[8] Reph, R. (1976). Space and placeness. London: Pilon.

[9] Ricoeur, P. (1990). Soi-même comme un autre. Paris: Seuil.

[10] Tuan, Y.-F. (1977). Space and place: the perspective of experience. Minnesota: University of Minnesota Press. 
[11] Tuan, Y.-F. (1990). Topophilia: A Study of Environmental Perception, Attitudes and Values. New York: Columbia University Press.

[12] Turco, A. (2002). Paesaggio: pratiche, linguaggi, mondi. Reggio Emilia: Diabasis.

[13] Turri, E. (1979). Semiologia del paesaggio italiano. Milano: Longanesi. 